\title{
EL DOBLE Y SU SUBVERSIÓN EN \\ EL CORAZÓN DEL TÁRTARO DE ROSA MONTERO ${ }^{1}$
}

\author{
Carmen García Armero
}

\begin{abstract}
El doble y su subversión en El corazón del tártaro de Rosa Montero
Resumen: Una lectura literal de El corazón del tártaro (2001) de Rosa Montero podría darnos la impresión de que solo se narra el acoso sufrido por Sofía Zarzamala a manos de su hermano gemelo y el proceso de maduración por el que atraviesa la protagonista. Sin embargo, una lectura interdisciplinaria y psicoanalítica revela que nos encontramos ante una novela de doppelgänger, en la que el enfrentamiento de la protagonista con su doble no finaliza con su desintegración, sino con la posibilidad de alcanzar una personalidad integrada. A través de este personaje femenino, Montero cuestiona y subvierte la tradición literaria del doble.

Palabras clave: doble, individuación, identidad, género, poder, patriarcado, memoria y tradición.
\end{abstract}

The Double and its Subversion in El Corazón del Tártaro by Rosa Montero

Abstract: A literal reading of El corazón del tártaro (2001) by Rosa Montero could give us the impression that the novel just narrates the harassment inflicted on Sofía Zarzamala by her twin brother and the process of maturity that the main character goes through. However, an interdisciplinary and psychoanalytic approach reveals that this narrative can be read as a doppelgänger novel. The protagonist's confrontation with her double does not end with her disintegration, but with the possibility of achieving an integrated personality. Through this feminine character, Montero questions and subverts the literary tradition of the double.

Key words: double, individuation, identity, gender, power, patriarchy, memory and tradition.

\section{Introducción}

Una lectura exclusivamente literal de El corazón del tártaro (2001) de Rosa Montero podría darnos la impresión de que solo se narra el angustioso acoso que sufre Sofía Zarzamala, Zarza, a manos de Nico, su hermano gemelo, y que "Zarza, como antes Agua Fría, Baba y Lucía Montero, va a completar también su propio proceso de maduración ("Bildungsroman”), lo que le permitirá conocerse mejor, reconciliarse con su

\footnotetext{
${ }^{1}$ Fecha de recepción: 30/10/2014.

Fecha de aceptación: 15/12/2014.

2 Profesora del Departamento de Lenguas, Lebanon Valley College, Annville, PA, Estados Unidos y

Doctora en Literatura española contemporánea; $₫$ cgarcia@lvc.edu.
} 
memoria y ordenar su propio universo personal" (Escudero 2005: 187) ${ }^{3}$. Esta investigación explora y muestra cómo una lectura interdisciplinaria y psicoanalítica revela que El corazón del tártaro se puede leer también como una novela de doppelgänger con una fuerte carga psicológica y simbólica. Desde esta perspectiva, la amenazante figura de Nico constituye un claro ejemplo del doble, ya que personifica las tendencias más oscuras, antisociales y destructoras inherentes tanto en la personalidad de la protagonista como de todo ser humano. El enfrentamiento con su hermano gemelo obliga a Zarza a rememorar dolorosas experiencias de un pasado traumático, cuyo recuerdo ha intentado enterrar y olvidar sin éxito. La rememoración de estos dolorosos acontecimientos posee una función catártica, ya que la aceptación consciente de ese oscuro pasado le permite a Zarza pasar de un estado de vida psíquico a otro, mediante un proceso de la psique al que Carl Jung calificó de individuación. Gracias a este proceso que, como en el caso de la protagonista, puede quedar paralizado al sufrir experiencias traumáticas, Zarza es capaz de salir del estado de muerte en vida, en el que por voluntad propia se había recluido durante años. Tiene así la posibilidad de madurar y desarrollar una personalidad integrada y estable. Uno de los aspectos más relevantes de esta novela radica, por lo tanto, en que el enfrentamiento de Zarza con su doble no supone su desintegración física y psíquica, como sucede en la mayor parte de relatos de doppelgänger que finalizan con la locura, el suicidio o la muerte del sujeto fragmentado, sino su integración o al menos la posibilidad de dicha integración gracias a la aceptación del amor. De este modo, Montero cuestiona y subvierte a su vez la tradición literaria del doble.

\section{EI tema mítico del doble en la literatura y su evolución}

El motivo del doble posee una gran antigüedad, pues se puede encontrar en textos literarios muy tempranos. En The Doppelgänger. Literature's Philosophy Dimitris

\footnotetext{
${ }^{3}$ La obra de Rosa Montero, una de las escritoras españolas contemporáneas más reconocidas, ha recibido gran atención por parte de la crítica especializada, principalmente su producción novelística. Para una reciente recopilación de estudios que abarca la totalidad de su obra -literatura y periodismo-, véase La incógnita desvelada. Ensayos sobre la obra de Rosa Montero editado por Ramos Mesonero (2012).
} 
Vardoulakis señala cómo tradicionalmente al hablar del doble se evocan ciertos ejemplos típicos, "such as the discussion of the "other half” by Aristophanes in Plato's Symposium, or the motif of Amphitryon, the myth of Narcissus, comedies of anagnorisis, not to mention all the examples of doubling and the shadow that anthropology has highlighted" (2010: 9). En el ámbito literario alcanza un auge sin precedentes en el siglo XIX debido, según Claire Rosenfield, a circunstancias tanto culturales como psicológicas; con los derechos del hombre se pone un nuevo énfasis sobre el individuo y el Romanticismo, no solo sanciona la introspección, sino que reintroduce en la sociedad la herencia colectiva del folklore (1967: 313). Sin embargo, hubo que esperar a que Sigmund Freud revelara la importancia de lo irracional en el ser humano, para que admitiéramos la posibilidad de que cada uno de nosotros posee un doble que se aloja junto a nuestro civilizado y racional "yo" (Rosenfield 1967: 311). Si bien Freud destacó la importancia del inconsciente en el individuo, Jung y Otto Rank han sido probablemente quienes han analizado con mayor precisión la relación existente entre el héroe y su doble. Rank estableció a su vez el nexo con las tendencias narcisistas intrínsecas en el ser humano apoyándose en principio en teorías freudianas. Sus primeros comentarios sobre el tema aparecieron en 1914 en un artículo titulado "Der Doppelgänger” y estimularon a su vez en Freud ciertas ideas, que éste expuso en otro seminal ensayo, “The Uncanny” (1919).

Para Carl Keppler, el motivo del doble aparece también con mayor frecuencia durante los siglos diecinueve y veinte porque o bien durante este periodo los escritores se han visto inevitablemente influenciados por la psicología, o bien tanto escritores como psicólogos han querido dar expresión a problemas específicos de la mente humana (1972: XII). En épocas anteriores, ciertos temas -como determinadas inclinaciones y excesos sexuales, el incesto, la necrofilia, etc.- eran tratados a través de obras pertenecientes al género fantástico por ser considerados tabúes. Al haberse convertido en la actualidad en elementos habituales de la vida social, la literatura los refleja como tales. Aparecen así explorados no solo en obras de carácter psicológico, sino incluso en la literatura infantil y juvenil que cuenta con muchos testimonios al respecto, por ejemplo, las obras de Jordi Sierra i Fabra. Asimismo, las recreaciones del doble como mito moderno han sido muy numerosas y utilizadas por autores tan destacados como Hoffmann, Poe, Dostoievski, 
Maupassant, Stevenson, Oscar Wilde, Pirandello, Borges, Cortázar y Saramago, entre otros muchos, como se indica en la editorial del número monográfico 3 de la revista de mitocrítica Amaltea (2011) .

Por otro lado, la palabra “doble” o “doppelgänger” fue simultáneamente introducida y acuñada tanto en el lenguaje como en la tradición literaria a finales del siglo XVIII por Jean Paul Richter en su novela Siebenkäs (1797) (Keppler 1972: 2). Al intentar definir de forma específica el término “doppelgänger” nos enfrentamos a una tarea bastante ardua, pues como Albert Guerard explica en su introducción a Stories of the Double, la crítica literaria emplea el concepto del doble con extrema vaguedad al no tener que referirse necesariamente ni a una alucinación autoscópica ni tampoco a cierto parecido físico entre los personajes (1967: 3). El problema se ve en parte agravado, en opinión de Clifford Hallam, porque el "doble" puede referirse no solo a cualquier estructura dual, sino incluso a múltiples estructuras dentro de un mismo texto (1981: 5). La siguiente definición que emplea Joanne Blum en su libro Transcending Gender. The Male/Female Double in Women's Fiction es bastante concisa, clarificadora y útil para este ensayo:

Usually the term "double" or "doppelgänger", is used to denote a kind of egodivision or fragmentation of self into dual, and sometimes multiple personalities. In general, one self is the more "realistic" character, the self with whom the reader identifies, and the other remains, to some extent, a "shadow self" which may exert either positive or negative influences on the first self. This second self, or shadow self, most often represents a repressed aspect of the first self, a physical acting-out of buried asocial behaviors, or simply of feelings, beliefs, or actions which the first self cannot express as his/her own. The double need not be physically embodied; it may be only a hallucinatory projection of some aspect of the self (as, for example, in Oscar Wilde's The Picture of Dorian Gray). Or it may appear to have both physical existence and independent motives (as in Conrad's “The Secret Sharer"). Often the physical reality of the double is left intentionally ambiguous, as in

\footnotetext{
${ }^{4}$ Para un análisis más amplio sobre el tema mítico del doble en la literatura y su evolución, se pueden consultar Keppler (1972), Rogers (1970), Hallam (1981: 1-31), Martín López (2006), Vardoulakis (2010), el excelente artículo de Herrero Cecilia (2011: 15-48) y el número monográfico 3 de Amaltea. Revista de Mitocrítica, entre otros muchos estudios.
} 
Dostoevsky's "The Double". In any case, whether it be hallucinatory or realistic, the traditional double implies some kind of psychic fragmentation which is projected from the troubled mind outward into the world. (1988: 2-3)

Blum considera también que el empleo de un doble "masculino/femenino" representa una estrategia importante mediante la cual las escritoras han intentado superar el confinamiento genérico impuesto por la sociedad patriarcal (1988: 1). En una entrevista con Kathleen Glenn publicada en 1990, Montero destaca lo codificados que nos encontramos tanto las mujeres como los hombres con respecto a la cultura en la que vivimos, donde la educación literaria recibida al igual que los mitos culturales son masculinos y cómo uno de los grandes retos de las mujeres escritoras, las mujeres artistas, radica en crear sus propios mitos femeninos (1990: 281) ${ }^{5}$. Por su parte, Pilar ValeroCosta ha comentado también al respecto cómo Rosa Montero "desde los últimos veinte años ha intentado manipular, ridiculizar y cuestionar los mitos perpetuados por el patriarcado, especialmente en lo referido a posiciones de poder, identidad y relaciones genéricas” (2007: 167) ${ }^{6}$. Como veremos a lo largo de este ensayo, en El corazón del tártaro Montero emplea un doble "masculino/femenino" no solo para ilustrar los conflictos internos que continuamente amenazan con desestabilizar al ser humano en el mundo contemporáneo, sino para intentar trascender el confinamiento genérico implantado por la cultura patriarcal.

\section{El corazón del tártaro: una novela de doppelgänger}

En esta obra se nos relata cómo desde su salida de la prisión y a sus 36 años de edad, Sofía Zarzamala vive encerrada en sí misma, refugiándose en su trabajo de editora

\footnotetext{
5 Para un comentario más detallado sobre la escritura y lectura femeninas, véase el artículo de Marino (2014): “Women's Writing and Women's Reading: Gender, Bibliography, Paths and Trends". Álabe 9 [www.revistaalabe.com].

${ }^{6}$ Genaro Pérez ha analizado cómo Montero subvierte de forma paródica las estructuras de la novela policíaca en El corazón del tártaro, Te trataré como a una reina y La hija del caníbal (2007: 347-360).
} 
y correctora de libros medievales. Su falta de autoestima, pues se considera "un fracaso existencial" (Montero 2001: 56), y el odio que siente hacia sí misma, manifestado en su incapacidad de contemplar su propia imagen en el espejo, le impiden alcanzar una personalidad equilibrada y estable. La desorientación, la confusión y la angustia-como a la mayoría de los personajes de la autora- la embargan en medio de un mundo absurdo y sin sentido, donde predominan el caos y la fragmentación ${ }^{7}$. Una inesperada llamada telefónica, con la que se inicia la intriga criminal del relato, altera su existencia solitaria, sin amigos, sin objetos y sin memoria que ha arrastrado durante los últimos años. Zarza se verá obligada a evocar sus dolorosas experiencias personales con el alcohol, la droga, la prostitución, la delincuencia y la cárcel. Asimismo, tendrá que reconocer el daño y las traiciones cometidas contra familiares y allegados, pero sobre todo contra sí misma al haber escogido durante años “el entumecimiento antes que el dolor” (Montero 2001: 195). La rememoración de ese doloroso pasado y el reconocimiento de los errores cometidos le permitirán no solo confrontar sus miedos y fantasmas personales y a través de este proceso reconciliarse con su memoria, sino cuestionar de forma consciente su identidad y su problemática existencial ${ }^{8}$.

\section{1. La inquietante figura del doble}

Concuerdo con Javier Escudero al sugerir que "en esta novela se utilizan más elementos típicos de la novela gótica, como la presentación de un personaje encerrado en un ambiente opresivo que huye de un pasado traumático, o las referencias al crimen, la crueldad, la perversión, la casa en ruinas o el espectro del mal" (2005: 186). Pero a estos elementos característicos de la ficción gótica hay que añadir la importante figura del doble o doppelgänger. En Fantasy. The Literature of Subversion Rosemary Jackson indica

\footnotetext{
${ }^{7}$ Para un análisis de los personajes en cuatro novelas de Montero: La función Delta, Te trataré como a una reina, Temblor y La hija del caníbal, se puede consultar el estudio de Torres (2004).

${ }^{8}$ La identidad y sus límites - un aspecto que adquiere suma relevancia en El corazón del tártaro y por el que Montero se siente cada vez más y más atraída- ocupa ya un lugar central en La hija del caníbal. Para un interesante estudio de la identidad y la liminalidad en esta última novela, véase Liminal Fiction at the Edge of the Millennium: The Ends of Spanish Identity de Folkart (2014), en concreto el capítulo 3.
} 
cómo el dualismo pasa a ser ya un tema central en las versiones góticas del siglo XIX en las que se desarrolla una literatura del doble, convirtiéndose en uno de los mitos literarios producidos por el deseo de otredad propio de esa época (1981: 108). Aunque existen muchas variantes entre el cuerpo físico y su doble (la sombra, el reflejo en el espejo, la fotografía, el cuadro, la estatua, la figura de cera, etc.), el ejemplo más famoso es entre cuerpo y cuerpo, como sucede en el caso de los gemelos. Zarza y Nico, además de ser hermanos gemelos, comparten otros rasgos típicos de la figura tradicional del doble. Por ejemplo, se complementan de forma tan absoluta que su complicidad llega a resultar inquietante al vivir desde la infancia en una isla, hermética y privada, "entregados el uno al otro, como náufragos en una situación desesperada" (Montero 2001: 170). Si bien Zarza es el personaje más realista, con el que el lector puede identificarse mejor, Nico aparece rodeado por un aura de misterio, lo que hace que en ciertos momentos parezca pertenecer a un orden distinto de la realidad. Según Keppler, el segundo "yo" se encuentra entre las sombras rodeado de un aura siniestra y esto permite que en ocasiones parezca que proviene de un tipo distinto de realidad. Conoce secretos y hechos que el personaje central ignora, de manera que no solo es el más extraño y el más fuerte, sino que tiende a dominar la relación que se establece entre ambos (1972: 11). Siempre en control de la relación, Nico, a quien Zarza lleva "muy dentro" (Montero 2001: 79) y llega a sentirlo tan pegado a sus talones como su "sombra" (Montero 2001: 79), se manifiesta exclusivamente a través de amenazas telefónicas o escritas de origen oscuro. Esta situación aumenta la ambigüedad que sobre su presencia real o imaginaria existe a lo largo de toda la novela.

Rank concluye en The Double (1925) que tanto la ambivalente relación de amor y odio como la rivalidad que surge entre el protagonista y su doble representan en realidad la lucha entre los conflictos internos que asaltan al individuo al enfrentarse consigo mismo. De este modo, la ambivalente y conflictiva relación de atracción y repulsión que Zarza mantiene con su gemelo representa la lucha entre los conflictos internos entre los que se debate la protagonista. Nico, "su perseguidor, su hermano, su verdugo" (Montero 2001: 63), "su demonio" (Montero 2001: 259) y “bersekir temible” (Montero 2001: 259) personifica las tendencias más oscuras, antisociales y destructoras, que continuamente amenazan con desestabilizar y destruir al ser humano, como la pasión desbordada, la 
capacidad de odio, las obsesiones, la violencia, los deseos incestuosos y el extremado narcisismo. Mientras Zarza se encuentra dominada y controlada por la nefasta influencia de Nico, su vida se ve inevitablemente abocada al mundo del alcohol, de la droga, de la prostitución y de la delincuencia, llegando a traicionar no solo a todos los que la rodean, sino sobre todo a sí misma. En la novela la leyenda de "El traidor Mirval" sirve también para ilustrar cómo cada uno de nosotros lleva dentro de sí mismo a su peor enemigo. Mirval acaba totalmente solo al ser el único habitante de un infierno que ha creado él mismo, pues sus miedos personales le hacen traicionar a todos los habitantes de su reino. Si como se indica en el relato, el traidor se convierte en un sujeto confundido, en "un suicida" (Montero 2001: 146), que al romper la continuidad de su propia imagen destruye su identidad, Zarza acaba perdiendo así la suya.

Frente a las tendencias más oscuras y destructoras de Zarza, personificadas en Nico (el doble amenazador característico de la literatura gótica y romántica), surge como contrapeso la inocencia de Miguel, su hermano pequeño, un individuo "raro, tardo de mente y de reflejos" (Montero 2001: 25), un “Ángel Tonto” (Montero 2001: 225). La figura de un doble benevolente (originalmente expresada mediante un ángel bueno que en visiones y sueños sirve de guía al personaje central en momentos críticos) aparece así encarnada en este personaje. El amor que le inspira Miguel le da a Zarza el valor suficiente para dejar de huir y presentar batalla a su perseguidor; es decir, afrontar sus miedos y fantasmas personales. Miguel le transmite además un mensaje alentador al ser todavía posible alcanzar la belleza en medio de tanto horror, pues es el único capaz de reordenar el viejo cubo de Rubik, metáfora del caos y del orden de la vida. A lo largo del camino Zarza va encontrando a diversos personajes que le dan el valor suficiente para seguir luchando. Aunque para Daniel, el barman del Desiré, la vida "es una pelea a muerte" (Montero 2001: 71), sin embargo, ha escogido luchar. Martillo proviene de un mundo cruel e infame, pero se respeta a sí misma. Incluso su hermana Martina, quien se ha construido una vida totalmente convencional y personifica todo lo que Zarza más detesta, se erige como un ejemplo más entre todas aquellas "personas dispuestas a tomar una 
opción, a luchar por ella, a pagar el precio necesario" (Montero 2001: 207) ${ }^{9}$. Esta nueva actitud contrasta con la postura derrotista que en principio Zarza manifiesta ante la vida y que comparte con Nico y con su madre, una madre enferma con tendencias suicidas ${ }^{10}$. Pero es el amor de pareja que le ofrece Urbano el que le da la fuerza suficiente para desear comenzar una nueva vida, cuyo origen al igual que los comienzos del universo se equipara a "la explosión de un coito luminoso" (Montero 2001: 251). El amor y el reconocimiento del "Otro" como ser humano hacen que las desgracias, la ruina personal y las injusticias de la vida puedan ser más llevaderas. Como señala Urbano, "Si no eres capaz de ver a los demás, tampoco puedes verte a ti mismo. Porque los demás, los que te rodean, la vida y los compromisos que te tocan, son los límites que te hacen ser quien eres. Y si no reconoces esos límites y esas responsabilidades, no eres nada, no eres nadie” (Montero 2001: 249).

\section{2. El motivo del viaje y el espacio}

El viaje de aproximadamente veinticuatro horas, que Zarza realiza por la ciudad intentando huir de la furia vengativa de su perseguidor, alude a nivel simbólico tanto a un viaje en el tiempo hacia ese traumático pasado que ha intentado olvidar durante años, como al antiguo mito o la experiencia arquetípica del viaje de la noche. Zarza desciende así a las zonas más profundas de ese terrible y horroroso "corazón del tártaro", a su propio infierno. La división interior que experimenta aparece a su vez reflejada en el espacio que la rodea. El contraste que se establece entre el mapa de la ciudad convencional y el de la urbe maldita (la ciudad de la "Reina", de la droga), superponiéndose ambas y compartiendo en ocasiones el mismo espacio con zonas "cándidas y burguesas durante el día, pero turbias y marginales de madrugada" (Montero 2001: 32) nos recuerda también

\footnotetext{
${ }^{9}$ La hermana melliza de la narradora y protagonista de la siguiente obra de Montero, La loca de la casa (2003), se llama también Martina. La novela comienza con el siguiente epígrafe: "Para Martina, que es y no es. Y que, no siendo, me ha enseñado mucho".

${ }^{10}$ Sandra Schumn considera que "symbolically, the illness and death of Zarza's mother represent the lack of strength and direction of women and mothers in Spanish society during Franco's dictatorship and afterwards" (2011: 80).
} 
el conflicto que Zarza mantiene con Nico. Aunque la protagonista pertenece a la clase media o burguesa, el ambiente canalla que tanto atrae a la escritora y que aparece de forma tan destacada en otras obras como Te trataré como a una reina (1983), Bella y oscura (1993), Instrucciones para salvar el mundo (2008) y Lágrimas en la lluvia (2011), resurge en El corazón del tártaro con gran ímpetu. La evocación de un ambiente lúgubre y tétrico, rasgo también típico de la novela gótica, le permite a Montero abordar problemas sociales de la actualidad: la marginación social, la drogadicción, la delincuencia, la violencia doméstica y sexual, la pederastia y el incesto del que Zarza cree haber sido víctima a manos de Nico y de su sádico padre. El tratamiento abierto de estos temas, especialmente relacionados con la sexualidad de la mujer, es un rasgo característico de la narrativa de Montero desde la publicación de su primera novela, Crónica del desamor (1979).

\section{3. Una sensación de inquietante extrañeza}

El ambiente de irrealidad y de delirio, el aura opresiva que envuelve todo y "la claustrofóbica sensación de algo ya vivido" (Montero 2001: 159) sirven para recrear una atmósfera siniestra y extraña, que produce horror, pero que al mismo tiempo nos acerca a lo casero y a lo familiar. Es el retorno de lo reprimido, que al lograr resurgir a la superficie hace que lo ya experimentado sea percibido de forma consciente como algo aterrador. Freud lo explica claramente en su seminal artículo "The Uncanny" (1919) al referirse al efecto siniestro y extraño que recrean ciertas experiencias, como sucede en el encuentro con el doble. En este ensayo Freud describe cómo psicológicamente el doble, un efecto que en ocasiones podemos encontrar también en textos literarios con personajes divididos, autómatas, fantasías, visiones y sueños, recrea un tipo de experiencia a la que se alude en alemán con el término "unheimlich" (lo "siniestro", lo "ominoso"). Por otro lado, la palabra opuesta "heimlich" (lo "casero", lo "familiar") puede en ciertas ocasiones, dependiendo del contexto o de las intenciones del hablante, ser sinónimo de "unheimlich" al referirse a lo extraño, a lo que produce horror. Según Freud, existe una explicación psicológica para este fenómeno, ya que "the uncanny is that class of the frightening which 
leads back to what is known of old and long familiar" (1961:220). Lo siniestro es similar a lo que los franceses denominan "déjà vu" ("lo ya visto"), con la diferencia de que lo ya experimentado ahora aparece envuelto en una atmósfera de terror. Consiste en aquello que debería haber permanecido reprimido y en el inconsciente, pero que ha logrado surgir a la superficie y ser percibido de forma consciente como algo aterrador. Para Freud, lo siniestro se encuentra claramente asociado tanto con el fenómeno de repetición, como la ansiedad que nos producen todas aquellas experiencias que nos recuerdan el irremediable destino del ser humano, la muerte ${ }^{11}$.

No sorprende que para enfrentarse a su gemelo Zarza regrese a su casa de la infancia, a la que se alude en la novela como "una representación del propio subconsciente" (Montero 2001: 138). Tampoco extraña que la protagonista la perciba como "un sepulcro" (Montero 2001: 137), "un agobiante laberinto" (Montero 2001: 138), "un cubo de Rubik entregado al caos" (Montero 2001: 138), "una de esas pesadillas geométricas que arden en el interior de nuestros cerebros cuando la fiebre nos devora" (Montero 2001: 138). Al fin y al cabo la casa representa "su propio cerebro troceado, un hervor de monstruos personales" (Montero 2001: 138). A Zarza le parece absurdo pensar que todo es "un problema de habitaciones, de cuartos clausurados, de alcobas amenazadoras o secretas" (Montero 2001: 229); en definitiva, "Un tumulto de moradas interiores, espacios dentro de espacios, cubos dentro de cubos, como el ingenioso artefacto de Rubik. Un caos monumental y trillonario" (Montero 2001: 230). Sin embargo, es necesario que se atreva simbólicamente a abrir esas puertas para enfrentarse de forma consciente a sus miedos y fantasmas del pasado, a todo aquello que durante años ha intentado reprimir, olvidar y silenciar sin éxito. A pesar de todo el dolor sufrido y el daño ocasionado, Zarza acepta la capacidad inherente en todo ser humano para hacer el bien y el mal, como su nombre, Sofía Zarzamala, indica a nivel simbólico al atreverse a enfrentarse y asumir conscientemente su oscuro pasado.

Durante la confrontación final con su perseguidor, Zarza cree ver "emergiendo borrosamente de las sombras" (Montero 2001: 265) detrás de su propia imagen el reflejo

\footnotetext{
${ }^{11}$ La teoría de Freud sobre la tendencia del ser humano hacia la repetición compulsiva de ciertas acciones aparece desarrollada en Beyond the Pleasure Principle.
} 
de una figura masculina, Nico o su padre, "ese papá-Dios, el padre araña” (Montero 2001: 56) ${ }^{12}$. Puesto que en las novelas del doble el perseguidor aparece con frecuencia encarnado en la figura del padre o de un sustituto, generalmente un hermano, no es de extrañar que al final del relato los dos personajes se confundan en una única imagen, cuya misteriosa identidad nunca llegará a desvelarse por completo, debido al parecido físico de ambos. Esto sirve para aumentar el aura de misterio y ambigüedad que predomina a lo largo de toda la narración. Pero, como ya dijimos al inicio de este ensayo, el enfrentamiento de Zarza con su doble no supone su desintegración física y psíquica; es decir, su muerte -como sucede en la mayor parte de relatos de doppelgänger que finalizan con la locura, el suicidio o la muerte del sujeto fragmentado-, sino su integración o al menos la posibilidad de dicha integración. Vardoulakis comenta lo siguiente al respecto:

Associated with death is the figure of following, accosting, or pursuing. The doppelgänger very often will pursue its other, or be pursued by it or both, which will usually be a prelude to a murder. This ineliminable pursuit is attested in the word 'Doppelgänger', since the compound name means literally a 'double-walker.' It is further attested in prevalent motifs of the doppelgänger, such as the pursuit by the shadow. (2010: 69)

\section{4. "El Caballero de la Rosa": un doble literario}

Montero introduce en la novela otra leyenda, "El Caballero de la Rosa", en la que la autora relata el amor y el odio, la rivalidad y la dependencia que arrastra a la lucha fratricida a dos hermanastros, uno bastardo, Edmundo, y otro legítimo, Gaon. Esta leyenda refleja de forma paralela y simétrica, como un doble literario, la conflictiva relación existente entre Zarza y Nico. Una primera versión del texto finaliza con la aniquilación mutua de ambos “como gemelos, los dos partiéndose el corazón, el uno al

\footnotetext{
${ }^{12}$ Biruté Ciplijauskaité ha señalado cómo "Según algunos críticos, la mujer solía verse incluso en el espejo siempre en segundo plano; el primer plano era ocupado por la imagen masculina (y no se refieren a los usos supersticiosos de algunas noches 'mágicas' en las cuales las muchachas pedían al espejo que les mostrara la figura del futuro marido)” (1988: 78).
} 
otro, en el definitivo abrazo de la muerte" (Montero 2001: 131). Este final representaría la imposibilidad de reconciliación entre las distintas partes del sujeto fragmentado y su inevitable destrucción al no poder escapar a su trágico destino. Sin embargo, Zarza descubre una segunda versión en la que los hermanastros tras luchar juntos contra los vikingos logran salvarse, separándose posteriormente para seguir cada uno su propio camino. Al final de la novela, Zarza decide incluir ambos desenlaces para su publicación, lo que implicaría no solo la desmitificación de la lucha fratricida como única vía de resolución ante los conflictos, sino la responsabilidad de cada individuo a nivel personal y colectivo ante la sociedad en la que vive inmerso.

\section{5. Un diseño circular y un final abierto}

Aunque hemos visto cómo en El corazón del tártaro se utilizan muchos elementos característicos de la ficción gótica, entre los que destaca el doble, esta obra no comparte la visión típica de la novela gótica. Según Jackson, dicha visión "is one lacking faith in organic notions of wholeness" (1981: 101), puesto que "Gothic inverts romance structures: the quest, for example, is twisted into a circular journey to nowhere, ending in the same darkness, with which it opened, remaining unenlightened" (1981: 101). En obras anteriores, como sucede en Amado amo (1988), Montero nos muestra el proceso de desintegración que hoy vive el individuo y la estructura circular de los capítulos refleja el mundo delirante de pesadilla donde el protagonista, César Miranda, está atrapado y del que no puede escapar. Por el contrario, la estructura circular de El corazón del tártaro sirve para destacar la transformación de Zarza gracias al proceso de integración y maduración por el que logra atravesar su psique. La rememoración de sus dolorosas experiencias, reprimidas e ignoradas durante años, y el reconocimiento de los errores cometidos poseen una función catártica, pues le permiten pasar de un estado psíquico inicial que puede calificarse de muerte en vida a otro lleno de optimismo y esperanza. Es fácil coincidir con Carmen Parrón cuando afirma que "La obra se propone demostrar que, pese al terrible ambiente en que puede transcurrir una infancia y adolescencia como las 
de Zarza, es posible liberarse de él; que no siempre triunfan la herencia biológica, las experiencias y vivencias familiares y la drogodependencia” (2007: 64). Se defiende así a través de un personaje femenino la posibilidad de transformación del ser humano y su capacidad de alcanzar una personalidad integrada y estable al poder (re)crear y (re)construir su propia identidad independientemente de la herencia biológica y las circunstancias familiares, económicas y sociales que hayan marcado su infancia ${ }^{13}$. Muy lejos queda la visión pesimista sobre la dificultad inherente en los personajes de la escritora de mejorar sus circunstancias personales y sociales tan marcada en sus obras iniciales. Si bien es cierto que el final de la novela posee un tono optimista y esperanzador, la amenaza que suponen tanto Nico como su padre no ha desaparecido por completo, ya que "podrían reaparecer en cualquier momento, peligrosos y enfermos y volver a hostigarla y perseguirla. O tal vez no" (Montero 2001: 267). Esta idea vendría a resaltar que el ser humano no se encuentra nunca totalmente a salvo de los peligros del pasado. Como lectores no sabemos si Zarza tendrá éxito o no en el futuro, debido al final abierto y ambiguo con el que concluye el relato y con el que se evoca tanto la incertidumbre de la vida como el sentido paradójico de la existencia que posee la autora.

\section{6. La fragilidad de la memoria}

Para Montero, "sólo esa mareante paradoja, el hecho de que novelar sea el arte de hilvanar mentiras con el fin de desvelar verdades, nos da una idea de la complejísima relación que mantienen la ficción y la realidad. Se contemplan mutuamente como en un espejo" (1992: 133). Es cierto que el testimonio de Zarza posee escasa fiabilidad, un rasgo que comparte con otros personajes de obras anteriores como Lucía (La hija del caníbal), Baba y Airelai (Bella y oscura), Océano (Temblor) y Lucía (La función Delta). En esta ocasión no se debe a que Zarza reconozca abiertamente haber mentido ni a su gusto por la imaginación -como ocurría en las novelas anteriormente citadas y como Escudero ha

\footnotetext{
${ }^{13}$ Para un análisis detallado sobre cómo Montero se opone en sus obras a la habitual creación de prototipos femeninos negativos, ver Nieva de la Paz (2009: 107-131).
} 
sugerido sobre estas obras (2005: 156)-, sino a un pasado marcado por la delincuencia, la droga y ciertas experiencias traumáticas. "Y así, Zarza creía que había mantenido relaciones prohibidas con su padre, pero Martina pensaba que no. El hombre del espejo podía haber sido Nicolás, pero también ese padre tal vez incestuoso" (Montero 2001: 268). La existencia de memorias diferentes e incluso enfrentadas, cuyas perspectivas resultan contradictorias mantiene al lector en la incertidumbre de si ciertos recuerdos y vivencias de la protagonista han sucedido realmente como Zarza los rememora o si solo han sido producto de una mente trastornada. Así se borran de nuevo los límites entre la realidad y la ficción debido a la fragilidad y maleabilidad de la memoria. Considero que es importante destacar el siguiente comentario que Jo Labanyi hace al aludir a este tema:

While memory does not give us reliable information about what happened in the past, it does record experiences that are mostly absent from official documents and, above all, it can play a central role in historical understanding by allowing us precisely to see how the past affects the present. For memory is always constructed from the vantage-point of the present. To reject memory as an unreliable witness to the past is to miss the point, for what memory reveals is present-day attitudes to the past. (2008: 122)

La novela muestra así tanto la necesidad que Zarza tiene de reconciliarse con un pasado que sigue actuando en su experiencia del presente como la dificultad de recuperarlo a través de sus recuerdos personales, ya que toda rememoración conlleva múltiples distorsiones.

La importancia que la memoria adquiere en el texto ha sido destacada por otros críticos. En "Algunas reflexiones sobre el postfeminismo apocalíptico en El corazón del tártaro e Historia del Rey Transparente de Rosa Montero", Parrón comenta cómo esta obra "pone en discusión la importancia de la memoria a través de la evocación de un pasado literario remoto al que se concede una atención especial" (2007: 65). En Mother and Myth in Spanish Novels. Rewriting the Maternal Archetype, Sandra Schumn establece la conexión existente en esta novela con el reciente pasado histórico de España. 
Esta crítica señala cómo "Zarza's voyage through her memories echoes the themes of many recent novels of remembrance" (2011: 81), pero su análisis se centra en la recuperación de la figura de la madre. Debido a la importancia que la rememoración del pasado adquiere en El corazón del tártaro, es difícil estar de acuerdo con Escudero cuando afirma que los conflictos que se presentan en esta obra en torno a la intriga de carácter criminal "no se relacionan tanto ahora con una dimensión social, ideológica o existencial, sino más bien con una problemática personal" (186). Por el contrario, la historia personal de Zarza podría leerse tanto como una alusión a la historia de España en particular como a la historia de la humanidad en general, a su vez llena de "realidades atroces y dolientes" (Montero 2001: 188).

El relato de Zarza puede parecer una excesiva acumulación de desgracias personales, como como se nos sugiere también en la obra, con un hermano anormal, el posible asesinato, suicidio o confusión de la madre, la violencia y el abuso psicológico, físico y sexual por parte del padre y de Nico, entre otras muchas tragedias. Sin embargo, esta historia tártara se convierte en una más de las múltiples realidades que imperan en el mundo, donde el horror de lo sucedido en muchas ocasiones supera con creces al de lo imaginado. Los ejemplos son innumerables, ya que "los mismos seres que eran capaces de imaginar el bien y la belleza destruían a renglón seguido sus propios logros con una ciega orgía de dolor. La historia de la humanidad era en realidad la historia de una traición” (Montero 2001: 189). Así pues, el tema se universaliza al aludir a conflictos eternos de la condición humana y se convierte también en una reflexión general sobre el ser humano y su dualidad.

\section{Conclusión}

Como hemos expuesto a lo largo de esta investigación, un acercamiento interdisciplinario y psicoanalítico nos permite interpretar El corazón del tártaro como una novela de doppelgänger con una fuerte carga psicológica y simbólica. Montero utiliza 
un doble "masculino/femenino", por un lado, para aludir a los conflictos internos que continuamente amenazan con desestabilizar al ser humano en el mundo contemporáneo y plantear ciertos interrogantes de carácter metafísico y existencial. Por otro, para intentar trascender el confinamiento genérico implantado por la cultura patriarcal. Asimismo, hemos visto cómo uno de los aspectos más destacados de esta novela consiste en que el enfrentamiento de Zarza con su doble Nico no finaliza con su desintegración física y psíquica; es decir, con su muerte, como suele suceder en la mayor parte de relatos de doppelgänger. Por el contrario, Zarza tiene la posibilidad de alcanzar una vida integrada y estable gracias al proceso de individuación por el que atraviesa su psique. De este modo, Montero cuestiona y subvierte la tradición literaria de doble.

\section{Referencias bibliográficas}

Blum, Joanne. 1988. The Male/Female Double in Women's Fiction. London: UMI Research Press.

Ciplijauskaité, Biruté. 1988. La novela femenina contemporánea (1970-1985): Hacia una tipología de la narración en primera persona. Barcelona: Anthropos.

“El doble / The Double Self”. 2011. Amaltea. Revista de mitocrítica 3, 2011. http://www.umc.es/info/amaltea/revista.html. [25 octubre. 2011]

Escudero, Javier. 2005. La narrativa de Rosa Montero: hacia una ética de la esperanza. Madrid: Biblioteca Nueva.

Folkart, Jessica A. 2014. Liminal Fiction at the Edge of the Millennium: The Ends of Spanish Identity. Lanham, MD: Bucknell University Press.

Freud, Sigmund. 1961. Beyond the Pleasure Principle. The Standard Edition of the Complete Psychological Works of Sigmund Freud. vol. XVIII. Ed. James Strachey. London: Hogarth. 7-64.

. "The Uncanny". 1961. The Standard Edition of the Complete Psychological Works of Sigmund Freud, vol. XVII. Ed. James Strachey. London: Hogarth. 217252. 
Glenn, Kathleen. 1990. "Conversación con Rosa Montero". Anales de la Literatura Española Contemporánea 15,1-3: 275-283.

Guerard. Albert J. 1967. "Concepts of the Double". Stories of the Double. Ed. Albert J Guerard. Philadelphia: J. B. Lippincott Company. 1-14.

Hallam, Clifford. 1981. "The Double as Incomplete Self: Toward a Definition of the Doppelgänger”. Fearful Symmetry: Doubles and Doubling in Literature and Film. Ed. Eugene J. Crook. Tallahassee: University Press of Florida. 1-31.

Herrero Cecilia, Juan. 2011. "Figuras y significaciones del mito del doble en la literatura: teorías explicativas". Cédille: revista de estudios franceses, 2: 15-48.

Jackson, Rosemary. 1981. Fantasy. The Literature of Subversion. Routledge: London \& New York.

Keppler, Carl. 1972. The Literature of the Second Self. Tucson: University of Arizona Press.

Labanyi, Jo. 2008. "The Politics of Memory in Contemporary Spain”. Journal of Spanish Cultural Studies, 9, 2: 119-125.

Marino, Toni. 2014. “Women's Writing and Women's Reading: Gender, Bibliography, Paths, and Trends". Álabe 9. http://www.revistaalabe.com. [20 enero 2015].

Martín López, Rebeca. 2006. Las manifestaciones del doble en la narrativa breve española contemporánea. Tesis doctoral. Barcelona: Universidad.

Montero, Rosa. 1988. Amado amo. Madrid: Debate.

. 1992. "Apuntes sobre la ficción y la realidad." España frente al siglo XXI:

Cultura literatura. Ed. Samuel Amell. Madrid: Cátedra. 133-138.

. 1993. Bella y oscura. Barcelona: Seix Barral.

. 2001. El corazón del tártaro. Madrid: Espasa.

. 1979. Crónica del desamor. Madrid: Debate.

. 2011. Lágrimas en la lluvia. Barcelona: Seix Barral.

. 1981. La función Delta. Madrid: Debate.

- 1997. La hija del caníbal. Madrid: Espasa.

- 2003. La loca de la casa. Madrid: Alfaguara.

. 2008. Instrucciones para salvar el mundo. Madrid: Alfaguara.

. 1990. Temblor. Barcelona: Seix Barral.

. 1983. Te trataré como a una reina. Barcelona: Seix Barral. 
Nieva de la Paz, Pilar. 2009. "Modelos femeninos de ruptura en la literatura de las escritoras Españolas del siglo XX: Concha Méndez (1898-1986), Carmen Martín Gaite (1925-2000) y Rosa Montero (1951- )". Foro hispánico: revista hispánica de Flandes y Holanda, 34: 107-131.

Parrón, Carmen. 2007. "Algunas reflexiones sobre el postfeminismo apocalíptico en El corazón del tártaro e Historia del Rey Transparente de Rosa Montero". Monographic Review/Revista Monográfica, 23: 60-70.

Pérez, Genaro. 2007. "Te trataré como a una reina, La hija del caníbal y El corazón del tártaro de Rosa Montero: Subversión paródica de estructuras de la novela policíaca". Letras peninsulares, 20, 2-3: 347-360.

Ramos Mesonero, Alicia, ed. 2012. La incógnita desvelada: Ensayos sobre la obra de Rosa Montero. Nueva York: Peter Lang Publishing.

Rank, Otto. 1971. The Double. Ed. Harry Tucker. Chapel Hill: The University of North Carolina Press.

Rogers, Robert. 1970. The Double in Literature. Detroit: Wayne State University Press.

Rosenfield, Claire. 1967. "The Shadow within: The Conscious and Unconscious Use of the Double". Stories of the Double. Ed. Albert J. Guerard. New York: Lippincott Company. 311-131.

Schumn, Sandra J. 2011. Mother and Myth in Spanish Novels. Rewriting the Maternal Archetype. Lanham, MD: Bucknell University Press.

Torres, Inmaculada. 2004. Rosa Montero: estudio del personaje en la novela. Málaga: Universidad.

Valero-Costa, Pilar. 2007. "Fantasía, ironía y doble conciencia narrativa: Herramientas desestabilizantes en la narrativa de Rosa Montero". Alba de América, 26, 49-50: 167-174.

Vardoulakis, Dimitris. 2010. The Doppelgänger. Literature's Philosophy. New York: Fordham University Press. 